\title{
Manufactures Human Over-the-Counter Drug Products Produced Under an Approved Drug Application
}

National Cancer Institute

\section{Source}

National Cancer Institute. Manufactures Human Over-the-Counter Drug Products

Produced Under an Approved Drug Application. NCI Thesaurus. Code C131709.

The process of manufacturing non-prescription medications under an approved drug application (as opposed to under a monograph), for humans by a pharmaceutical company. 